\title{
Packaging Composite Films Fabricated from Cellulose Pulp with Polyurethane and Curcumin by Using NMMO ionic Liquid Solvent
}

\section{Chaehyun Jo}

Yeungnam University

\section{Sam Soo Kim}

Yeungnam University

\section{Srinivasan Ramalingam}

Yeungnam University

\section{Prabakaran D. S}

Yeungnam University

Balasubramanian Rukmanikrishnan ( $\nabla$ rukmibala@gmail.com )

Yeungnam University https://orcid.org/0000-0001-6207-7271

Jaewoong Lee

Yeungnam University

\section{Research Article}

Keywords: Cellulose pulp, polyurethane, curcumin, antioxidant properties, non-cytotoxicity, barrier properties, mechanical properties

Posted Date: November 23rd, 2021

DOI: https://doi.org/10.21203/rs.3.rs-1063688/v1

License: (c) (1) This work is licensed under a Creative Commons Attribution 4.0 International License. Read Full License 


\section{Abstract}

Cellulose pulp (CP), polyurethane (PU), and curcumin-based biocompatible composite films were prepared using a simple cost-effective method. These materials dissolved well in the ionic liquid solvent $\mathrm{N}$-methylmorpholine $\mathrm{N}$-oxide. Significant structural and microstructural changes were observed in $\mathrm{CP}$ upon the addition of PU. These changes were studied using Fourier transform infrared spectroscopy, Xray diffraction, and scanning electron microscopy. The $5 \%$ and $10 \%$ gravimetric losses of the $\mathrm{CP} / \mathrm{PU} /$ curcumin composite were found to be in the range $87.2-182.3^{\circ} \mathrm{C}$ and $166.7-249.8^{\circ} \mathrm{C}$, respectively. The addition of PU significantly improved the thermal stability and water barrier properties of the composites. All the composites exhibited single $\mathrm{T}_{\mathrm{g}}$ values in the range $147.4-154.2^{\circ} \mathrm{C}$. The tensile strength of $\mathrm{CP}$ was measured to be 93.2 MPa, which dropped to 14.1 MPa for the 1:0.5 CP/PU composite and then steadily increased to $30.5 \mathrm{MPa}$ with further addition of PU. The elongation at break of the composites decreased from 8.1 to $3.7 \%$ with the addition of PU. The addition of PU also improved the water vapor permeability $\left(3.96 \times 10^{-9}\right.$ to $\left.1.75 \times 10^{-9} \mathrm{~g} \mathrm{~m}^{-1} \mathrm{~s}^{-1} \mathrm{~Pa}^{-1}\right)$ and swelling ratio (285 to $\left.202 \%\right)$ of the $\mathrm{CP}$ composite films. The CP/PU/curcumin composite exhibited good antioxidant activity and no cytotoxicity when tested on the HaCat cell line. The visual appearance and UV transmittance (86.2-32.9\% at $600 \mathrm{~nm}$ ) of the $\mathrm{CP}$ composite films were significantly altered by the incorporation of PU and curcumin. This study demonstrates that $\mathrm{CP} / \mathrm{PU} /$ curcumin composites can be used for various packaging and biomedical applications.

\section{Introduction}

In recent years, sustainable and environmentally friendly materials have garnered significant attention in both scientific and industrial research fields. This is because they are abundant; low-cost; present low risk to animals, humans, and other living organisms; carbon neutral, biodegradable; and biocompatible (Sha et al. 2018; Antonio et al. 2008; Natalia et al. 2015; Juho et al. 2019; Rong-Lan et al. 2009). Among natural biopolymer resources, biomass has evolved as a value-added product for various industrial applications. Cellulose pulp (CP) is the most abundant, renewable, and inexpensive lignocellulosic material consisting of D-glycopyronose units, which is widely used in the paper and agricultural industries (Quanqing et al. 2019; Cortés-Triviño et al. 2018; Sara et al. 2012; Anwar et al. 2019). However, the brittleness and solubility of cellulose pulp restrict its application. Owing to its partly crystalline and partly amorphous structure, cellulose pulp is poorly soluble in many organic solvents (Wil et al. 2012; Xinping et al. 2020; Anamaria et al. 2012; Helena et al. 2012; Qiyang et al. 2013; Alcala et al. 2013; Hasan et al. 2019; Prodyut et al. 2015). A combination of $10 \% \mathrm{NaOH}, \mathrm{NaOH} / \mathrm{urea}$, and DMA/LiCl can dissolve cellulose pulp but it requires a relatively lengthy pre-treatment process. Ionic liquids are promising green solvents for dissolving cellulose pulp and are rapidly replacing organic solvents. Moreover, they have been used to prepare various composites by blending cellulose, wood pulp, and chitosan (Ronny et al. 2013; Xiaofei et al. 2017).

The addition of organic polymers, inorganic nanoparticles, and natural fillers to polymer backbones has gained popularity because they help improve the thermal, mechanical, and water barrier properties of 
composites. For instance, polyurethane (PU) is a block copolymer consisting of both soft and hard segments. PU-based composites have been extensively studied and widely used in polymer and materials sciences owing to their excellent mechanical, gas barrier, and water barrier properties (Alex et al. 2014; He et al. 2013; Zhenzhong et al. 2014; Dan et al. 2019; Andres et al. 2015; Seydibeyoglu et al. 2008). They have several biomedical applications, such as in the field of tissue engineering; they also have important medical and industrial applications because of their exceptional biocompatibility and biodegradability. A synergistic combination of cellulose pulp and PU has been shown to reduce the dependence on synthetic resources to a certain degree; in addition, such plant-based natural fiber-reinforced polymer matrix composites promote the use of renewable resources (Kai et al. 2019; Sang et al. 2013; Xuelin et al. 2014; Saralegi et al. 2013; Izaskun et al. 2020).

Turmeric (Curcuma longa) is a rhizomatous perennial plant. It is a rich source of phenolic compounds, such as curcuminoids. Curcumin (1, 7-bis(4-hydroxy-3-methoxyphenyl)-1, 6-heptadiene-3, 5-dione) is a natural bioactive compound extracted from turmeric powder. It has a low molecular weight and a phenolic structure consisting of $a, \beta$-unsaturated carbonyl groups. Curcumin has various therapeutic applications because of its antimicrobial, antioxidant, and anti-inflammatory properties. Moreover, it is compatible with different types of polymers (Kangkang et al. 2021; Gao et al. 2021; Balasubramanian et al. 2021a; Balasubramanian et al. 2021b; Chaehyun et al. 2021; Balasubramanian et al. 2021c). We hypothesize that the incorporation of PU and curcumin into CP can improve the antioxidant, mechanical, and thermal properties of the resulting composite films.

To test our hypothesis, in this study, we prepared composites based on a synergistic combination of $\mathrm{CP}$, $\mathrm{PU}$, and curcumin by simple dissolution in $\mathrm{N}$-methylmorpholine $\mathrm{N}$-oxide (NMMO) solvent. We thoroughly investigated the thermal, mechanical, and water barrier properties of these sustainable composites by performing Fourier transform infrared (FT-IR) spectroscopy, X-ray diffraction (XRD), scanning electron microscopy (SEM), and UV spectroscopy. In addition, we examined the antioxidant activity and cytotoxicity of these CP/PU/curcumin composites. In this study, we highlight the properties that make these composites suitable for packaging applications.

\section{Experimental Section}

\section{Materials}

Cellulose pulp was purchased from Moorim P \& P Co., Ltd., South Korea and curcumin was purchased from Sigma-Aldrich, South Korea. NMMO and turmeric powder were purchased from Dajang Chemicals, South Korea. Polyurethane (Elastollan ${ }^{\circledR} 1283$ D11 U) was purchased from BASF, South Korea. Watersoluble tetrazolium salt (WST-1) cat. \#EZ-1000 cytox was purchased from Daeil Lab Service Co., South Korea, to measure cytotoxicity. Note that all the reagents were used as received without further purification.

\section{Preparation of CP/PU/Curcumin Composite Films}


First, CP (4 g), PU (4 g), and curcumin (10 wt\%) were mixed thoroughly using a hand blender. Next, the $\mathrm{CP} / \mathrm{PU} /$ curcumin mixture was dispersed in a round-bottom (RB) flask containing NMMO $(92 \mathrm{~g})$ and heated to $100^{\circ} \mathrm{C}$. The RB flask was tightly closed and dipped in an oil bath to maintain uniform temperature and avoid recrystallization of the NMMO solvent at the top of the flask. After $2.3 \mathrm{~h}$, the RB flask was removed and kept in a vacuum oven at $100^{\circ} \mathrm{C}$ for another $6 \mathrm{~h}$ to completely remove air bubbles. Subsequently, a viscous $\mathrm{CP} / \mathrm{PU} /$ curcumin solution at $80^{\circ} \mathrm{C}$ was spread uniformly on a glass surface. The glass plate was immediately transferred to a coagulation bath containing water, where it was kept for $6 \mathrm{~h}$ and fresh water was transferred every $1 \mathrm{~h}$ without disturbing the film. Following the complete removal of the solvent from the $\mathrm{CP} / \mathrm{PU} /$ curcumin composite film, it was transferred to another glass plate and dried at room temperature for $48 \mathrm{~h}$. The thickness of the resulting transparent films was in the range $0.07-0.10 \mathrm{~mm}$. A series of composite films were prepared using a similar method, such that they consisted of only CP; 1:0.5 CP/PU; 1:1 CP/PU; and 1:1 CP/PU with $10 \mathrm{wt} \%$ turmeric powder.

\section{Results And Discussion}

\section{FT-IR Spectroscopy}

Figure 1 shows the FT-IR spectra of various CP/PU composite films. The broad band observed at 3100$3450 \mathrm{~cm}^{-1}$ (for both $\mathrm{CP}$ and $\mathrm{CP} / \mathrm{PU}$ composites) corresponds to the stretching vibration of the $\mathrm{O}-\mathrm{H}$ bond. The peaks at $2893 \mathrm{~cm}^{-1}$ and $1367 \mathrm{~cm}^{-1}$ correspond to the stretching vibrations of the $\mathrm{C}-\mathrm{H}$ bond and bending vibrations of the $\mathrm{O}-\mathrm{H}$ bond in cellulose, respectively. The peak at $858 \mathrm{~cm}^{-1}$ results from the vibrations of the $\mathrm{C}-\mathrm{H}$ bond, which is commonly observed in neat cellulose pulp (Ahmed et al. 2015; Shiv et al. 2016). The band at $895 \mathrm{~cm}^{-1}$ can be attributed to the stretching vibrations of $C-O-C$ in the $\beta-(1-4)$ glycosidic linkages of cellulose, which is considered to be in the amorphous phase. PU showed characteristic bands at $1697 \mathrm{~cm}^{-1}, 1313 \mathrm{~cm}^{-1}$, and $1231 \mathrm{~cm}^{-1}$ owing to the stretching vibrations of $\mathrm{C}=0$, $\mathrm{C}-\mathrm{N}$, and $\mathrm{C}-\mathrm{O}$ in the urethane group, respectively (Mehran et al. 2020). PU also exhibited bands corresponding to the carbonyl $\left(1650-1850 \mathrm{~cm}^{-1}\right)$, amide $\left(1420-1650 \mathrm{~cm}^{-1}\right)$ and ether $\left(910-1250 \mathrm{~cm}^{-1}\right)$

groups. The characteristic peaks of curcumin at $1652 \mathrm{~cm}^{-1}, 1516 \mathrm{~cm}^{-1}$, and $1446 \mathrm{~cm}^{-1}$ correspond to the vibrations of the carbonyl group $\mathrm{C}=0$, stretching vibrations of the $\mathrm{C}-\mathrm{C}$ bond in the benzene ring, and olefinic bending vibrations of the $\mathrm{C}-\mathrm{H}$ bond in the benzene ring, respectively. The intensity and positions of the peaks in the 1:1 CP/PU composite spectrum were observed to change when $10 \mathrm{wt} \%$ curcumin was added, indicating that the $\mathrm{CP}, \mathrm{PU}$, and curcumin bonded with each other in the $\mathrm{CP} / \mathrm{PU} /$ curcumin composite. Characteristic peaks at $1357 \mathrm{~cm}^{-1}$ (C-O-H bending), $1017 \mathrm{~cm}^{-1}$ (C-O stretching), and 1704 $\mathrm{cm}^{-1}$ (PU-carbonyl group) shifted to lower wavenumbers, namely, 1372, 1056, and $1697 \mathrm{~cm}^{-1}$, respectively. These results suggest that intermolecular interactions were present in the CP/PU/curcumin composite films.

\section{XRD Analysis}


The reinforcement effect of TPU on CP was characterized using XRD analysis, and the corresponding XRD patterns are shown in Figure 2. It is well known that the width and intensity of the peaks in an XRD pattern are related to the crystalline structure of the underling material. The XRD pattern of neat CP exhibited a peak about $2 \theta=16-23^{\circ}$, which indicates a crystalline phase. However, after the dissolution of $\mathrm{PU}$, the structure of $\mathrm{CP}$ changed, and the diffraction peaks of the 1:0.5 CP/PU and 1:1 CP/PU composites were observed to shift. The amorphous nature of PU significantly altered the intensity of the XRD peaks and a broad peak was exhibited by the $1: 1 \mathrm{CP} / \mathrm{PU}$ composite with $10 \mathrm{wt} \%$ curcumin. The crystallinity of the CP/PU composites gradually decreased owing to the dissolution of PU in the $\mathrm{CP}$ matrix. Broader peaks indicate an increase in the amorphous phase of the CP composites, which in turn increases the solubility of the composites in the NMMO solvent and helps form intermolecular hydrogen bonds between the components. The addition of PU to CP increased its amorphous nature such that the XRD peaks of the CP/PU composites were relatively broad with high intensity. Furthermore, peak shifts were observed in the XRD patterns of the CP/PU and CP/PU/curcumin composite films. The XRD pattern of curcumin showed intense diffraction peaks between $10^{\circ}$ and $30^{\circ}$ owing to its highly crystalline structure. The substantial decrease in the peak intensity of the $\mathrm{CP} / \mathrm{PU} /$ curcumin composite clearly indicates that curcumin is covalently linked with the polymer backbone. The absence of peaks corresponding to curcumin in the XRD pattern of 1:1 CP/PU composite with $10 \mathrm{wt} \%$ curcumin indicates that curcumin is properly combined with the CP/PU biopolymer matrix and is present in a low-order or amorphous state. These results confirm the proper dispersion of materials in the solvent and are in good agreement with the results of previous studies (Quanqing et al. 2019; Chaehyun et al. 2021; Qiuju et al. 2007; Ni et al. 2019; Yanxu et al. 2020; Aji et al. 2005).

\section{UV Spectroscopy}

The thickness of the CP/PU/curcumin composite films was in the range 0.07-0.1. The surface color and visual appearance of the $\mathrm{CP}$ films were affected owing to the addition of PU. The neat $\mathrm{CP}$ films appeared translucent, whereas the 1:0.5 CP/PU, 1:1 CP/PU, and 1:1 CP/PU with $10 \mathrm{wt} \%$ curcumin films appeared slightly opaque. The Hunter L* (lightness) value of the composites decreased, whereas the Hunter a* (redness) and $b^{*}$ (yellowness) values increased with increasing PU content. The neat CP composite film was colorless and transparent; however, the composite films containing PU and curcumin exhibited a yellow color. The UV transmittance of the CP/PU/curcumin composites as a function of wavelength is shown in Figure 3 (also, see Table 1). The UV transmittance of neat CP was $86.2 \%$ at $600 \mathrm{~mm}$; however, it decreased significantly after the incorporation of PU. The transmittance of 1:0.5 CP/PU, 1:1 CP/PU, and $1: 1 \mathrm{CP} / \mathrm{PU}$ with $10 \mathrm{wt} \%$ curcumin were $65.1,41.2$, and $32.9 \%$, respectively. Note that the $1: 1 \mathrm{CP} / \mathrm{PU}$ composite and 1:1 CP/PU composite with $10 \mathrm{wt} \%$ curcumin almost completely blocked the UV light below $400 \mathrm{~mm}$. This indicates that the materials were well dispersed in the solvent and the resulting composites are suitable for packaging applications.

\section{Water Vapor Permeability}


The WVP of the CP/PU/curcumin composites was measured to determine their water barrier properties, and the corresponding data are summarized in Table 1. The WVP of neat CP was measured to be $3.96 \times$ $10^{-9} \mathrm{~g} \mathrm{~m}^{-1} \mathrm{~s}^{-1} \mathrm{~Pa}^{-1}$, which decreased to $2.34 \times 10^{-9} \mathrm{~g} \mathrm{~m}^{-1} \mathrm{~s}^{-1} \mathrm{~Pa}^{-1}$ on the addition of PU. Note that both $\mathrm{PU}$ and turmeric powder are hydrophobic in nature; moreover, when PU and turmeric powder are dispersed throughout the CP matrix, a tortuous path for the diffusion of water molecules is created that increases the diffusion path length. The WVP of the 1:1 CP/PU composite was $1.81 \times 10^{-9} \mathrm{~g} \mathrm{~m}^{-1} \mathrm{~s}^{-1} \mathrm{~Pa}^{-1}$, which decreased to $1.75 \times 10^{-9} \mathrm{~g} \mathrm{~m}^{-1} \mathrm{~s}^{-1} \mathrm{~Pa}^{-1}$ on the addition of turmeric powder. Note that the reduced hydrophilicity of the $\mathrm{CP} / \mathrm{PU} /$ curcumin composites makes them suitable for packaging applications.

\section{Swelling Ratio}

The swelling behavior of the CP/PU/curcumin composites was studied in water at $25^{\circ} \mathrm{C}$. A low swelling ability is attributed to a high cross-link density of the composite films. This is because at higher cross-link densities, water permeation into the matrix becomes more difficult, which in turn affects the swelling capacity of the gel. The SR of neat CP decreased from $285 \%$ to $262 \%$ on the addition of PU. Thus, the SR of neat CP was $32 \%$ higher than that of the $1: 1 \mathrm{CP} / \mathrm{PU}$ composite. The SR further decreased to $202 \%$ for the CP/PU-1:1 composite with $10 \mathrm{wt} \%$ curcumin. Therefore, the hydrophobic nature of PU and curcumin significantly affects the swelling properties of $\mathrm{CP}$.

\section{Contact Angle}

The surface hydrophilicity/hydrophobicity of the composite films is an important determining factor for packaging applications. It is determined by measuring the water CA, whose values are listed in Table 1 . The results indicate that the addition of PU increased the hydrophobicity of the composite films. The CA of neat $\mathrm{CP}$ was $51.4^{\circ}$, which increased to $55.6^{\circ}$ and $58.2^{\circ}$ for the $1: 0.5 \mathrm{CP} / \mathrm{PU}$ and $1: 1 \mathrm{CP} / \mathrm{PU}$ composites, respectively. Furthermore, the addition of curcumin slightly increased the CA of the 1:1 CP/PU composite film. This is owing to the hydrophobic nature of the curcumin fillers, which hinder the diffusion of water molecules through the composite films. This result is consistent with the SR values of the $\mathrm{CP} / \mathrm{PU} /$ curcumin composites. 
Table 1. UV-transmittance, thickness, and color values of the CP/TPU/curcumin composite films.

\begin{tabular}{|c|c|c|c|c|c|}
\hline Sample & $\begin{array}{l}\text { Thickness } \\
(\mathrm{mm})\end{array}$ & $\begin{array}{l}\mathrm{T} \\
\text { (\%) } \\
\text { at } \\
600 \\
\mathrm{~nm}\end{array}$ & $\begin{array}{l}\text { Water vapor permeability } \\
\left(\times 10^{-9} \mathrm{gm} / \mathrm{m}^{2} \mathrm{Pas}\right)\end{array}$ & $\begin{array}{l}\text { Water } \\
\text { contact } \\
\text { angle }\left({ }^{\circ}\right)\end{array}$ & $\begin{array}{l}\text { Swelling } \\
\text { ratio (\%) }\end{array}$ \\
\hline
\end{tabular}
Only CP
0.07
$86.2 \quad 3.96$
51.4
285

$1: 0.5 \mathrm{CP} / \mathrm{TPU}$

$1: 1 \mathrm{CP} / \mathrm{TPU}$

1:1 CP/TPU with 10

wt $\%$ of curcumin
0.09

0.10

0.09

$32.9 \quad 1.75$

$65.1 \quad 2.34$

$\begin{array}{ll}41.2 & 1.81\end{array}$

58.2

215

55.6

262

60.1

202

\section{Thermogravimetric Analysis}

The characteristic thermal stability of the $\mathrm{CP} / \mathrm{PU} /$ curcumin composites was studied using TGA in an $\mathrm{O}_{2}$ atmosphere and the results are presented in Figure 4 and Table 2. All composites exhibited three stages of weight loss. PU significantly improved the thermal stability of CP. The $5 \%$ and $10 \%$ gravimetric losses of the composites were in the range $87.2-182.3^{\circ} \mathrm{C}$ and $166.7-249.8^{\circ} \mathrm{C}$, respectively. The initial degradation temperature of neat $\mathrm{CP}$ was $87.2^{\circ} \mathrm{C}$, which increased to $136.8,172.1$, and $182.3^{\circ} \mathrm{C}$ for the 1:0.5 CP/PU, 1:1 CP/PU, and 1:1 CP/PU with $10 \mathrm{wt} \%$ curcumin composites, respectively. We found that adding PU to the $\mathrm{CP}$ matrix caused a shift in the first and third degradation temperatures towards higher temperatures (approximately $130-230^{\circ} \mathrm{C}$ and $250-450^{\circ} \mathrm{C}$, respectively). However, the weight loss was nearly constant during the second degradation stage. The char yield of neat $\mathrm{CP}$ was $7.8 \%$, which increased to $15.7 \%$ for the $1: 1 \mathrm{CP} / \mathrm{PU}$ with $10 \mathrm{wt} \%$ curcumin composite. The improvement in the thermal stability of the CP/PU/curcumin composite can be ascribed to a confined network structure and uniform dispersion of the components in the polymer matrix. Furthermore, the incorporation of PU leads to synergistic interfacial interactions, which slows down the thermal decomposition of these composite films (Xuelin et al. 2014; Mehran et al. 2020).

\section{Differential Scanning Calorimetry}


The DSC thermogram revealed $\mathrm{T}_{\mathrm{g}}$ and $\mathrm{T}_{\mathrm{m}}$ of the CP/PU/curcumin composites and the results are summarized in Table 2 and Figure 5. Addition of PU seemed to improve $T_{g}$ and $T_{m}$ of neat CP. The 1:1 $\mathrm{CP} / \mathrm{PU}$ with $10 \mathrm{wt} \%$ curcumin composite exhibited the highest $\mathrm{T}_{\mathrm{g}}\left(154.2^{\circ} \mathrm{C}\right)$ and $\mathrm{T}_{\mathrm{m}}\left(204.2^{\circ} \mathrm{C}\right)$ values, which is owing to the higher order interactions and relaxation mechanisms in this composite. All composite films exhibited single $T_{g}$ and $T_{m}$ peaks. However, the intensity of the $T_{m}$ peaks decreased with the addition of $\mathrm{PU}$ to the composites. The significant improvement in the $\mathrm{T}_{\mathrm{g}}$ and $\mathrm{T}_{\mathrm{m}}$ values indicates the restricted molecular motion in the composite network, which is formed by the covalent cross-linking and strong hydrogen bonding between the $\mathrm{CP}$ and PU networks. These results are consistent with that of the XRD analysis and the mechanical properties of the composites (Kai et al. 2019; Mehran et al. 2020; Francisco et al. 2019; Ru et al. 2014).

\section{Mechanical Properties}

The mechanical properties of the CP/PU/curcumin composites are listed in Table 2. The tensile strength (TS) of neat CP was 93.2 MPa; however, it decreased to $14.1 \mathrm{MPa}$ in the 1:0.5 CP/PU composite. The TS increased again to $29.5 \mathrm{MPa}$ in the 1:1 CP/PU composite. The sudden decrease in TS was due to the dilution effect-poor adhesion between the polymer matrices leads to the formation of numerous voids at the matrix interface. The elongation at break (EB) of the CP/PU/curcumin composites was in the range $8.1-3.7 \%$. This decrease in EB on the addition of PU can be attributed to a decrease in polymer extensibility, which is caused by the formation of microphase separations in the composite films. These results are consistent with those of the SEM analysis, which revealed the CP/PU/curcumin composites to have an uneven and rough surface that may be responsible for the low EB (Wu et al. 2017). Note that a low aspect ratio and particulate nature can also lead to a low EB (Aji et al. 2005). Overall, the $\mathrm{CP} / \mathrm{PU} /$ curcumin composites were found to be hard and brittle in nature. 
Table 2. Thermal properties, mechanical properties, WVP, and CA of the CP/PU/curcumin composite films.

\begin{tabular}{|c|c|c|c|c|c|c|c|}
\hline \multirow{2}{*}{ Sample } & \multicolumn{3}{|l|}{ TGA } & \multicolumn{2}{|l|}{ DSC } & \multirow{2}{*}{$\begin{array}{l}\text { Tensile } \\
\text { strength } \\
\text { (MPa) }\end{array}$} & \multirow{2}{*}{$\begin{array}{l}\text { Elongation } \\
\text { at break } \\
(\%)\end{array}$} \\
\hline & $\mathrm{T}_{5 \%}$ & $\mathrm{~T}_{10 \%}$ & $\begin{array}{l}\mathrm{CY} \\
(\%)\end{array}$ & $\mathrm{T}_{\mathrm{g}}\left({ }^{\circ} \mathrm{C}\right)$ & $\mathrm{T}_{\mathrm{m}}\left({ }^{\circ} \mathrm{C}\right)$ & & \\
\hline Only CP & 87.2 & 166.7 & 7.8 & 147.4 & 187.3 & 93.2 & 8.1 \\
\hline 1:0.5 CP/TPU & 136.8 & 227.7 & 11.5 & 151.2 & 191.1 & 14.1 & 3.7 \\
\hline 1:1 CP/TPU & 172.1 & 247.5 & 14.8 & 153.4 & 202.4 & 29.5 & 3.9 \\
\hline $\begin{array}{l}1: 1 \mathrm{CP} / \mathrm{TPU} \text { with } 10 \mathrm{wt} \% \\
\text { of curcumin }\end{array}$ & 182.3 & 249.8 & 15.7 & 154.2 & 204.2 & 30.5 & 3.7 \\
\hline
\end{tabular}

\section{SEM Analysis}

We performed an SEM analysis to study the surface morphology of the CP/PU/curcumin composites. Figures 6 and 7 show the surface and cross-sectional SEM images of the composite films, respectively. The neat CP film had a homogenous surface without any agglomerates. However, the 1:0.5 CP/PU and 1:1 CP/PU composites had less homogenous surfaces; in addition, they exhibited small, uneven, and discontinuous voids. The cross-sectional image of the neat $\mathrm{CP}$ film shows that it has a slightly rough and uneven surface. The addition of PU increased the surface roughness of the composites; however, PU was uniformly distributed throughout the fractured surface. Note that these results are consistent with the mechanical properties of the composite films. The voids and cavities revealed by the cross-sectional SEM images are the main cause of the low TS and EB of the CP/PU/curcumin composite films.

\section{Antioxidant Activity}

Packaging films that have antioxidant properties are extremely effective in protecting food materials. The antioxidant activity of the CP/PU/curcumin composite films was determined using the DPPH radical scavenging activity (see Figure 8). As expected, the neat $\mathrm{CP}, 1: 0.5 \mathrm{CP} / \mathrm{PU}$, and 1:1 CP/PU composites showed no antioxidant activity. Curcumin is well known for its strong antioxidant activity, as it acts as a superoxide radical scavenger and singlet oxygen quencher. The 1:1 CP/PU with $10 \mathrm{wt} \%$ curcumin composite showed good antioxidant activity $(24.8 \%)$ after an incubation period of $1 \mathrm{~h}$. Turmeric is reported to have good thermal stability, as heating does not affect its active compounds such as 
curcumin and phenolic hydroxyl groups. Some studies have pointed out that the $\beta$-diketone moiety plays an important role in the antioxidant mechanism of curcumin; for instance, the donation of an $\mathrm{H}$-atom from the $\beta$-diketone moiety to a lipid alkyl or a lipid peroxyl radical has been shown to contribute to the antioxidant activity of curcumin. The high antioxidant activity of the CP/PU/curcumin composites makes them potential candidates for antioxidant food packaging material.

\section{Cytotoxicity}

Cell viability is an essential parameter to test the biosafety of a material. The cytotoxicity of the synthesized CP, CP/PU, and CP/PU/curcumin composites was evaluated using the WST-1 assay method on human keratinocyte cells (i.e., the HaCaT cell line), and the results are summarized in Figures 9 and 10. All the different composites were found to be non-cytotoxic. There was no difference in cell viability between the control and neat $\mathrm{CP}$ films. However, cell viability decreased in the 1:0.5 CP/PU and 1:1 CP/PU composites. Note that the cell viability of the 1:1 CP/PU with $10 \mathrm{wt} \%$ curcumin composite was better than that of the other $\mathrm{CP} / \mathrm{PU}$ composites. The decrease in cell viability was caused by cellular stress owing to the presence of a foreign element in the cell medium. The cell viability of the $1: 1 \mathrm{CP} / \mathrm{PU}$ with $10 \mathrm{wt} \%$ curcumin composite was $91 \%$, which can be attributed to the disappearance of cellular growth that is favorable for cell proliferation. The above results show that the CP/PU/curcumin composites are biocompatible and safe to be used for packaging applications.

\section{Conclusions}

In this study, we successfully blended two sustainable materials, namely, CP and turmeric powder, with a commercially available synthetic material, namely, PU, using an ionic solvent, namely, NMMO. The apparent color and UV transmittance of the composite films were significantly changed owing to the addition of PU. XRD analysis showed that PU decreased the overall crystallinity of CP. SEM analysis revealed that although all the components were uniformly dispersed in the polymer matrix, the composites had a rough and uneven surface that affected their mechanical properties. The TS of neat CP was 93.2 MPa, which decreased to 14.1 MPa for the 1:0.5 CP/PU composite and increased to $29.5 \mathrm{MPa}$ for the 1:1 CP/PU composite. However, the EB of CP declined monotonically with the addition of PU. The $\mathrm{CP} / \mathrm{PU} /$ curcumin composite also exhibited excellent thermal stability. The $\mathrm{T}_{\mathrm{g}}$ and $\mathrm{T}_{5 \%}$ values of the composites were in the range $147.4-154.2^{\circ} \mathrm{C}$ and $87.2-182.3^{\circ} \mathrm{C}$, respectively. Moreover, the addition of $\mathrm{PU}$ and curcumin to the CP matrix decreased the hydrophilicity of the CP/PU/curcumin composite, which in turn improved the water barrier properties and SR of the CP/PU/curcumin composite. The $\mathrm{CP} / \mathrm{PU} /$ curcumin composite exhibited excellent antioxidant properties and all the composites were found to be non-cytotoxic when tested on the HaCaT cell line. Nevertheless, further research is required to better understand the mechanical properties of these composites and to establish their utility in packaging applications.

\section{Declarations}




\section{Conflicts of interest}

There are no conflicts to declare.

\section{Funding Sources}

The authors declare no competing financial interest.

\section{References}

Ahmed AO, Jong-Whan R (2015) Preparation and characterization of sodium carboxymethyl cellulose/cotton linter cellulose nanofibril composite films. Carbohydr Polym 127:101-109.

Aji PM, Kristiina O, Mohini S (2005) Mechanical Properties of Biodegradable Composites from Poly Lactic Acid (PLA) and Microcrystalline Cellulose (MCC). J Appl Polym Sci 97: 2014-2025.

Alcala M, Gonzalez I, Boufi S, Vilaseca F, Mutje P (2013) All-cellulose composites from unbleached hardwood kraft pulp reinforced with nanofibrillated cellulose. Cellulose 20:2909-2921.

Alex OS, Luciano HSR, Luiz FM, Michael J da Silva, Walter KS, Jose AM (2014) Influence of cellulose nanofibrils on soft and hard segments of polyurethane/cellulose nanocomposites and effect of humidity on their mechanical properties. Polym Testing 40:99-105.

Anamaria S, Raluca ND, Marian T, Georgeta C, Cornelia V (2012) Low density polyethylene composites containing cellulose pulp fibers. Composites: Part B 43:1873-1880.

Andres IC, Javier IA, Elena F, Jose MK, Leonel MC (2015) The role of nanocrystalline cellulose on the microstructure of foamed castor-oil polyurethane nanocomposites. Carbohydr Polym 134:110-118.

Antonio NN, Hiroyuki Y (2008) The effect of fiber content on the mechanical and thermal expansion properties of biocomposites based on microfibrillated cellulose. Cellulose 15:555-559.

Anwar JS, Lalaso VM, Niteen AD, Dipak VP (2019) Structural characterization of cellulose pulp in aqueous NMMO solution under the process conditions of lyocell slurry. Carbohydr Polym 206:220-228.

Balasubramanian R, Srinivasan R, Sam SK, Jaewoong L (2021a) Rheological and anti-microbial study of silica and silver nanoparticles-reinforced k-carrageenan/hydroxyethyl cellulose composites for food packaging applications. Cellulose 28:5577-5590.

Balasubramanian R, Srinivasan R, Jaewoong L (2021b) Quaternary ammonium silane-reinforced agar/polyacrylamide composites for packaging applications. Int J Biol Macromol 182:1301-1309.

Balasubramanian R, Srinivasan R, Jaewoong L (2021c) Barrier, rheological and antimicrobial properties of sustainable nanocomposites based on gellan gum/polyacrylamide/zinc oxide. Polym Eng Sci 61:2477-2486. 
Chaehyun J, Balasubramanian R, Prabakaran DS, Srinivasan R, Jaewoong L (2021) Cellulose pulp-based stretchable composite film with hydroxyethyl cellulose and turmeric powder for packaging applications. ACS Sustainable Chem Eng 9:13653-13662.

Cortés-Triviño E, Valencia C, Delgado MA, Franco JM (2018) Rheology of epoxidized cellulose pulp gellike dispersions in castor oil: Influence of epoxidation degree and the epoxide chemical structure. Carbohydr Polym 199:563-571.

Dan C, Pingdong W, Lina Z, Jie C (2019) New Approach for the Fabrication of Carboxymethyl Cellulose Nanofibrils and the Reinforcement Effect in Water-Borne Polyurethane. ACS Sustainable Chem Eng 7:11850-11860.

Francisco L, Dejin J, Jiaqi G, Daniel H, Alexander E, Andreas W (2019) Outstanding Synergies in Mechanical Properties of Bioinspired Cellulose Nanofibril Nanocomposites using Self-Cross-Linking Polyurethanes. ACS Appl Polym Mater 1:3334-3342.

Gao YZ, Chen JC, Wu YX (2021) Amphiphilic Graft Copolymers of Quaternized Alginate-g-Polytetrahydrofuran for Anti-protein Surfaces, Curcumin Carriers, and Antibacterial Materials. ACS Appl Polym Mater 3:3465-3477.

Hasan M, Tze KL, Deepu AG, Jawaid M, Owolabi FAT, Mistar EM, Tata A, Noriman NZ, Haafiz MKM, Abdul Khalil HPS (2019) Micro Crystalline Bamboo Cellulose Based Seaweed Biodegradable Composite Films for Sustainable Packaging Material. J Polym Environ 27:1602-1612.

He L, Shuqin C, Shibin S, Dan W, Jie S (2013) Properties of rosin-based waterborne polyurethanes/cellulose nanocrystals composites. Carbohydr Polym 96:510- 515.

Helena N, Sylvain G, Larsson PT, Kristofer GE, Tommy I (2012) Compression molded wood pulp biocomposites: a study of hemicellulose influence on cellulose supramolecular structure and material properties. Cellulose 19:751-760.

Izaskun L, Julen V, Arantzazu SE, Alvaro T, Maider A, Eneritz V, Ander O, Ainara S, Aitor A, Arantxa E (2020) The effect of the carboxylation degree on cellulose nanofibers and waterborne polyurethane/cellulose nanofiber nanocomposites properties. Polym Degrad Stab 173:109084.

Juho AS, Miikka V (2019) Highly Transparent Nanocomposites Based on Poly(vinyl alcohol) and Sulfated UV-Absorbing Wood Nanofibers. Biomacromolecules 20:2413-2420.

Kai L, Pingdong W, Junchao H, Duoduo X, Yi Z, Lei H, Lina Z, Jie C (2019) Mechanically Strong ShapeMemory and Solvent-Resistant Double-Network Polyurethane/Nanoporous Cellulose Gel Nanocomposites. ACS Sustainable Chem Eng 7:15974-15982.

Kangkang Z, Huilan Y, Zhongguo S, Kerang H, Min Z, Xiaodong X (2021) Dual-modified starch nanospheres encapsulated with curcumin by self-assembly: Structure, physicochemical properties and 
anti-inflammatory activity. Int J Biol Macromol 191:305-314.

Mehran G, Fugen D, Elena PI, Billy JM, Benu A (2020) Use of Synergistic Interactions to Fabricate Transparent and Mechanically Robust Nanohybrids Based on Starch, Non-Isocyanate Polyurethanes, and Cellulose Nanocrystals. ACS Appl Mater Interfaces 12:47865-47878.

Natalia H, Aji PM, Kristiina O (2015) Plasticized polylactic acid/cellulose nanocomposites prepared using melt-extrusion and liquid feeding: Mechanical, thermal and optical properties. Compos Sci Technol 106:149-155.

Ni Z, Peng T, Yanxv L, Shuangxi N (2019) Effect of lignin on the thermal stability of cellulose nanofibrils produced from bagasse pulp. Cellulose 26:7823-7835.

Prodyut D, Debashis T, Amit K, Vimal K (2015) Effect of cellulose nanocrystal polymorphs on mechanical, barrier and thermal properties of poly(lactic acid) based bionanocomposites. RSC Adv 5:60426-60440.

Qiuju W, Marielle H, Xiaohui L, Lars AB (2007) A High Strength Nanocomposite Based on Microcrystalline Cellulose and Polyurethane. Biomacromolecules 8:3687-3692.

Qiyang W, Jie C, Lina Z, Min X, He C, Charles CH, Shigenori K, Jun X, Rui X (2013) A bioplastic with high strength constructed from a cellulose hydrogel by changing the aggregated structure. J Mater Chem A $1: 6678-6686$.

Quanqing H, Xin G, Heng Z, Keli C, Lincai P, Qingmin J (2019) Preparation and comparative assessment of regenerated cellulose films from corn (Zea mays) stalk pulp fines in DMAc/LiCl solution. Carbohydr Polym 218:315-323.

Rong-Lan W, Xiu-Li W, Fang L, Hui-Zhang L, Yu-Zhong W (2009) Green composite films prepared from cellulose, starch and lignin in room-temperature ionic liquid. Bioresource Technol 100:2569-2574.

Ronny W, Alistair K, Arno P, Kristiina K, Anna S (2013) Cellulose hydrolysis with thermo- and alkali-tolerant cellulases in cellulose-dissolving superbase ionic liquids. RSC Adv 3:20001-20009.

Ru L, Yao P, Jinzhen C, Yu C (2014) Comparison on properties of lignocellulosic flour/polymer composites by using wood, cellulose, and lignin flours as fillers. Compos Sci Technol 103:1-7.

Sang H, Park K, Wha O, Seong HK (2013) Reinforcement effect of cellulose nanowhisker on bio-based polyurethane. Compos Sci Technol 86:82-88.

Sara RL, Jari SK, Katja S, Janne A, Ilkka K (2012) Reactive dissolution of cellulose and pulp through acylation in pyridine. Cellulose 19:1295-1304.

Saralegi A, Rueda L, Martin L, Arbelaiz A, Eceiza A, Corcuera MA (2013) From elastomeric to rigid polyurethane/cellulose nanocrystal bionanocomposites. Composites Sci Technol 88:39-47. 
Seydibeyoglu MO, Oksman K (2008) Novel nanocomposites based on polyurethane and micro fibrillated cellulose. Composites Sci Technol 68:908-914.

Sha D, Jinrui M, Yilan G, Feng C, Qiang F (2018) One-step modification and nanofibrillation of microfibrillated cellulose for simultaneously reinforcing and toughening of poly( $\varepsilon$-caprolactone). Compos Sci Technol 157:168-177.

Shiv S, Jong-Whan R (2016) Preparation of nanocellulose from micro-crystalline cellulose: The effect on the performance and properties of agar-based composite films. Carbohydr Polym 135:18-26.

Wil VSI, Srikanth P, Zachary CW, Cecily AR, Joseph PG, Curtis WF, Sarah LB (2012) Mechanisms and impact of fiber-matrix compatibilization techniques on the material characterization of PHBV/oak wood flour engineered biobased composites. Compos Sci Technol 72:708-715.

Wu GM, Liu GF, Chena J, Kong ZW (2017) Preparation and properties of thermoset composite films from two-component waterborne polyurethane with low loading level nanofibrillated cellulose. Prog Org Coatings 106:170-176.

Xiaofei L, Zongbao L, Li W, Shengsheng Z, Hai Z (2017) Preparation and performance of composite films based on 2-(2-aminoethoxy) ethyl chitosan and cellulose. RSC Adv 7:13707-13713.

Xinping L, Xin Z, Shuangquan Y, Hui C, Yaoyu W, Zhao Z (2020) UV-blocking, transparent and hazy cellulose nanopaper with superior strength based on varied components of poplar mechanical pulp. Cellulose 27:6563-6576.

Xuelin Y, Xiaodong Q, Yuling H, Dongsheng T, Feng C, Qiang F (2014) Simultaneous Reinforcing and Toughening of Polyurethane via Grafting on the Surface of Microfibrillated Cellulose. ACS Appl Mater Interfaces 6:2497-2507.

Yanxu L, Peng T, Ni Z, Shuangxi N (2020) Preparation and thermal stability evaluation of cellulose nanofibrils from bagasse pulp with differing hemicelluloses contents. Carbohydr Polym 245:116463.

Zhenzhong G, Jun P, Tuhua Z, Jin S, Xiaobo W, Chao Y (2012) Biocompatible elastomer of waterborne polyurethane based on castor oil and polyethylene glycol with cellulose nanocrystals, Carbohydr Polym 87:2068- 2075.

\section{Figures}




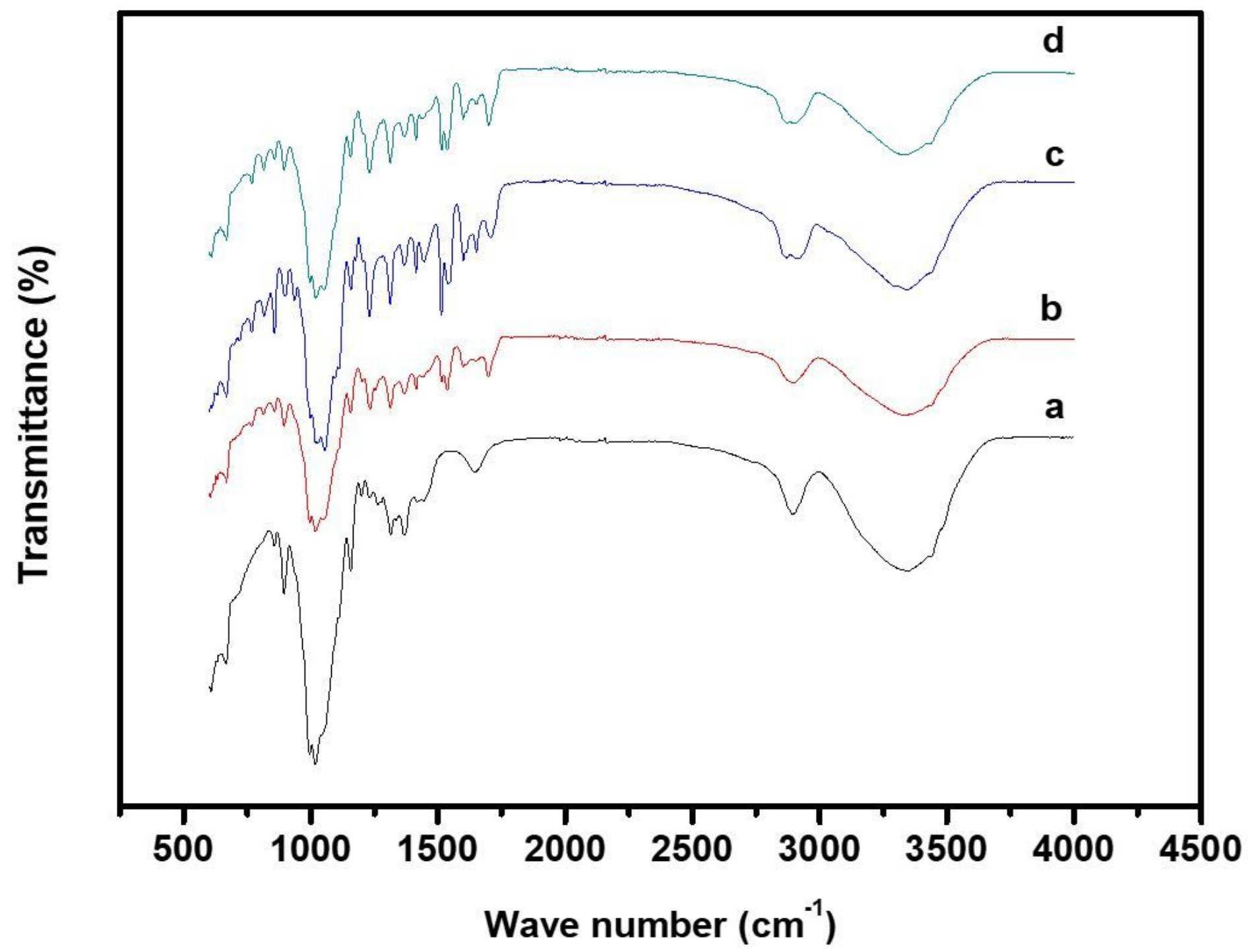

Figure 1

FT-IR spectra of composite films having: (a) only CP, (b) 1:0.5 CP/PU, (c) 1:1 CP/PU, and (d) 1:1 CP/PU with 10 wt\% curcumin. 


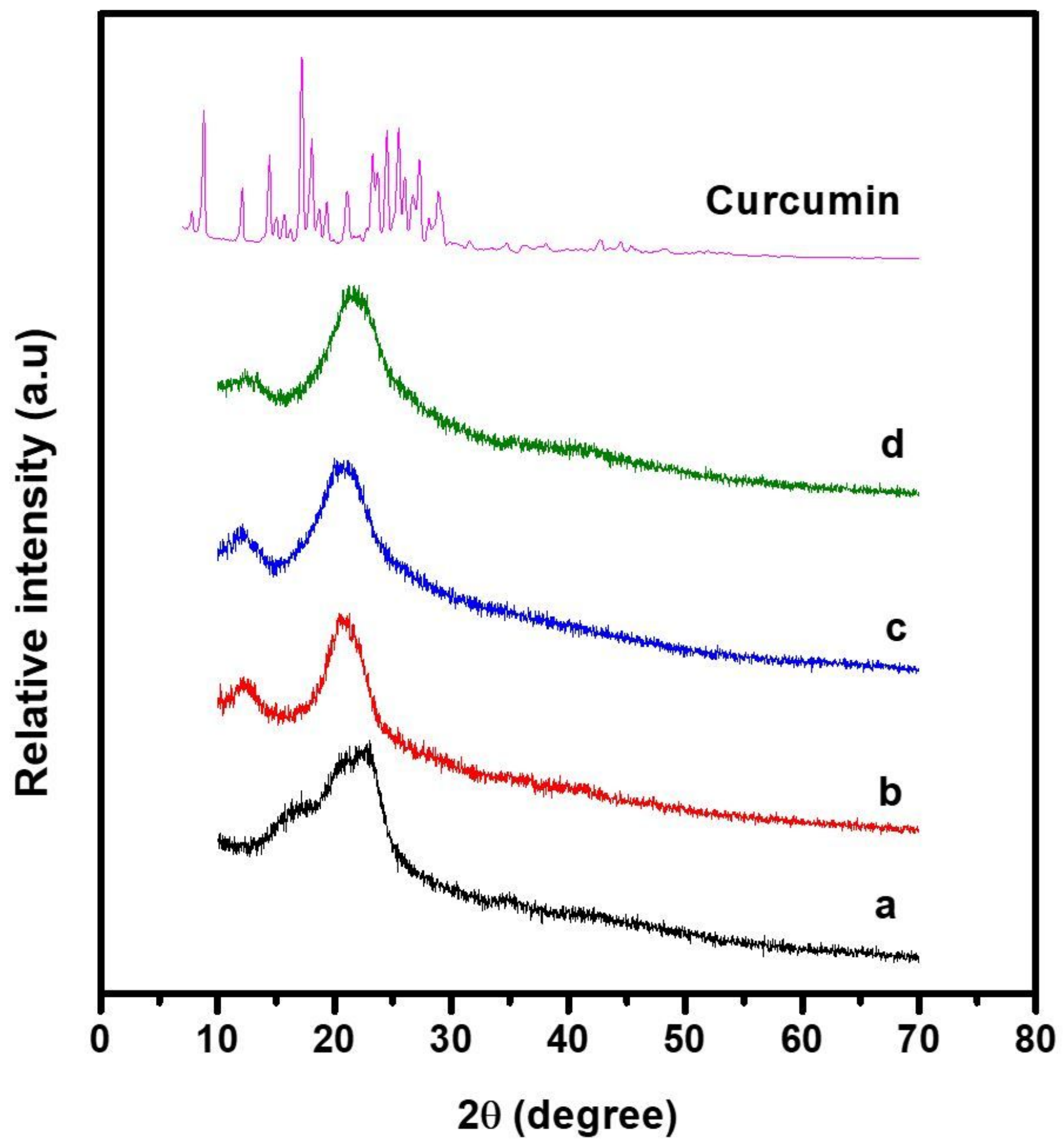

Figure 2

XRD patterns of composite films having: (a) only $\mathrm{CP}$, (b) 1:0.5 CP/PU, (c) 1:1 CP/PU, and (d) 1:1 CP/PU with 10 wt\% curcumin. 


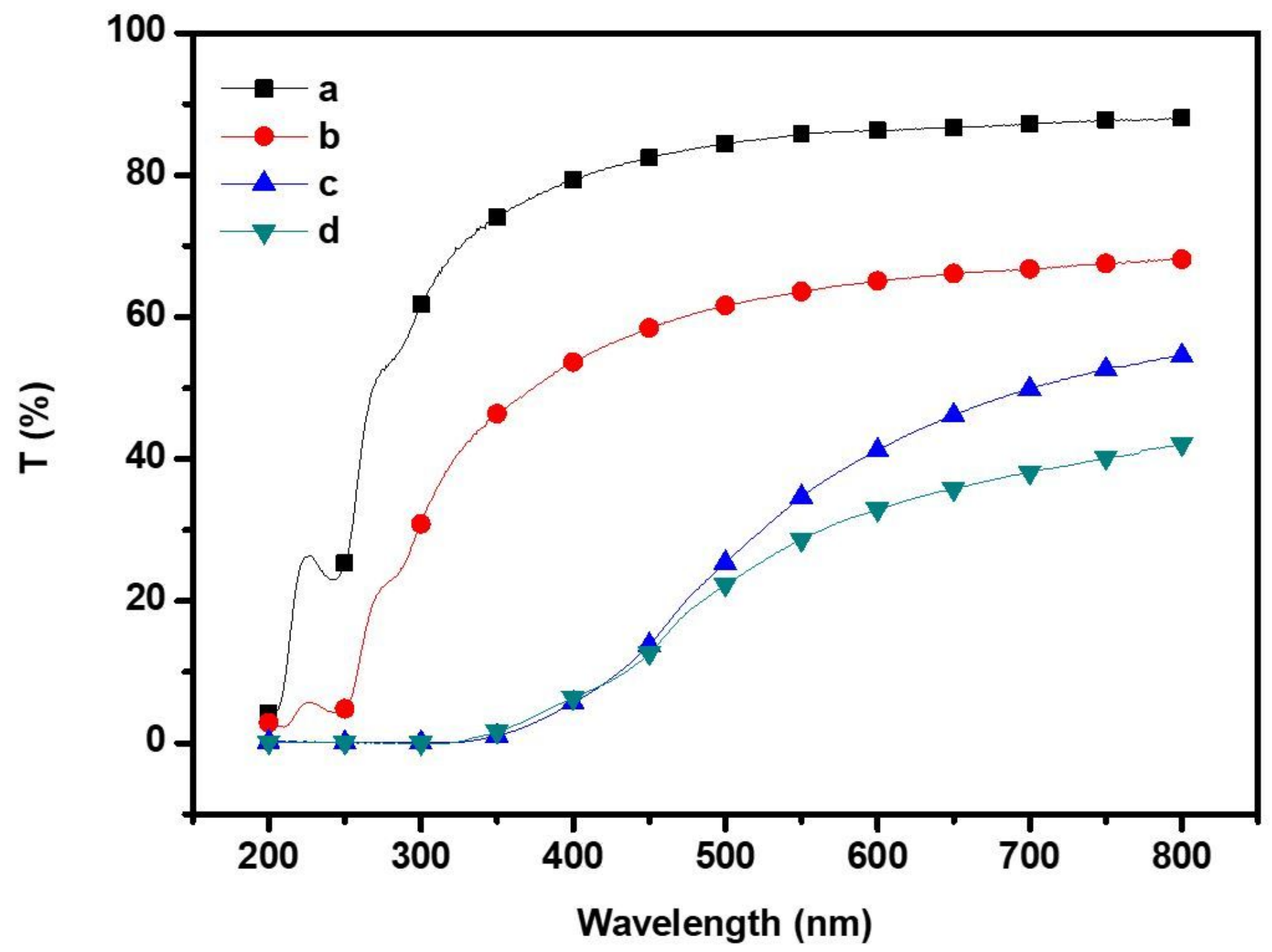

Figure 3

UV transmittance spectra of composite films having: (a) only CP, (b) 1:0.5 CP/PU, (c) 1:1 CP/PU, and (d) 1:1 CP/PU with 10 wt\% curcumin. 


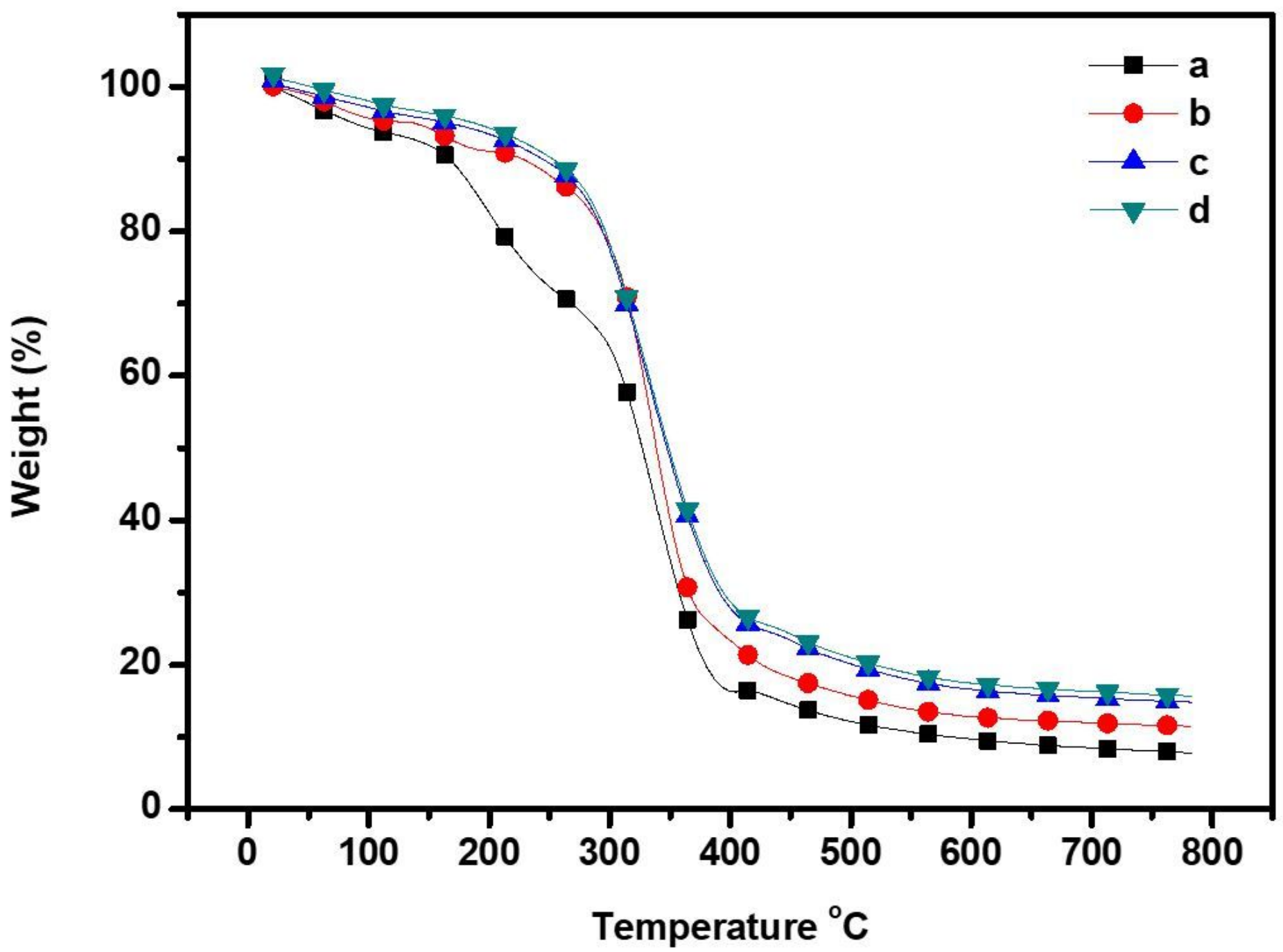

Figure 4

TGA curves of composites having: (a) only CP, (b) 1:0.5 CP/PU, (c) 1:1 CP/PU, and (d) 1:1 CP/PU with 10 wt\% curcumin. 


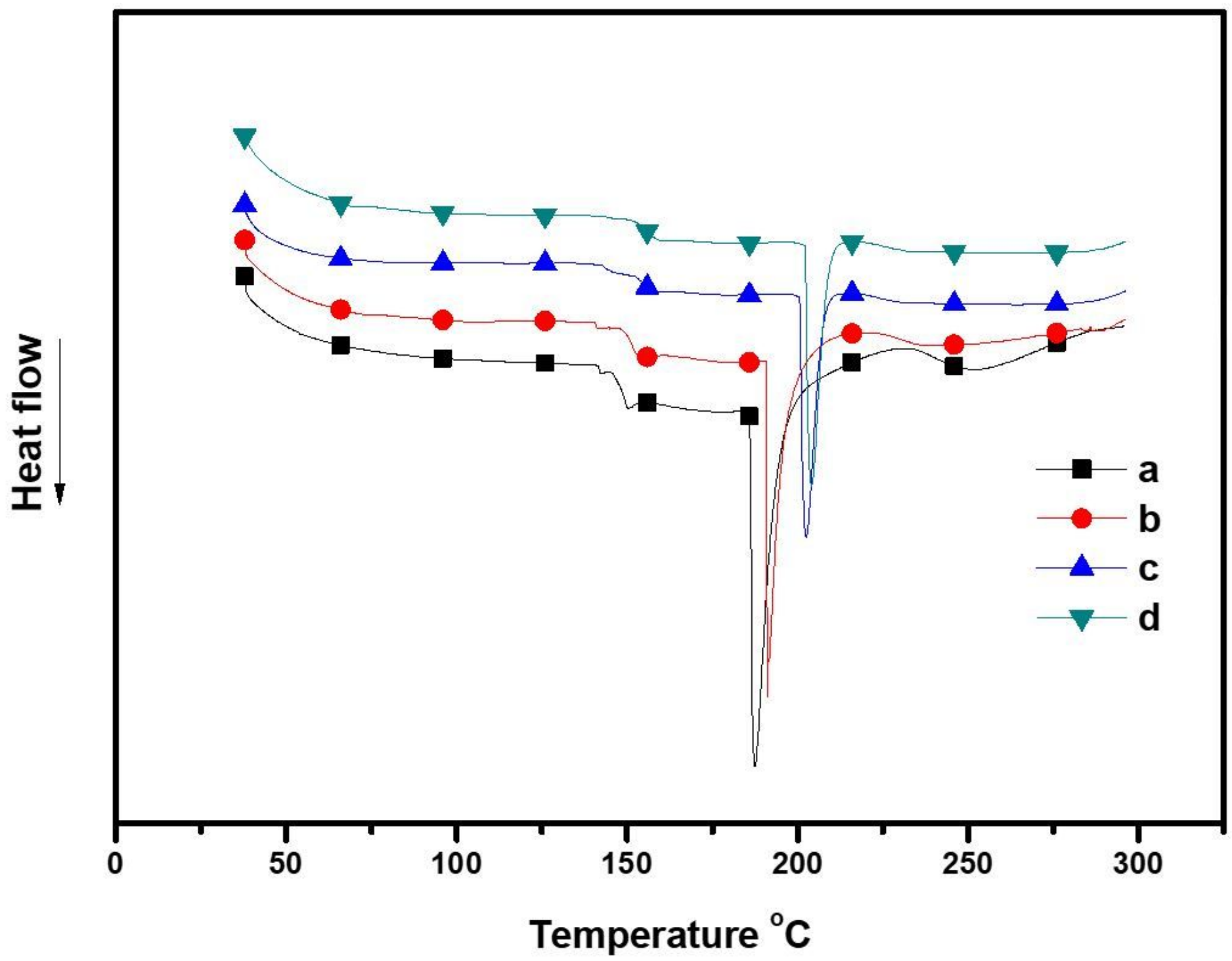

Figure 5

DSC thermogram of composites having: (a) only CP, (b) 1:0.5 CP/PU, (c) 1:1 CP/PU, and (d) 1:1 CP/PU with $10 \mathrm{wt} \%$ curcumin. 

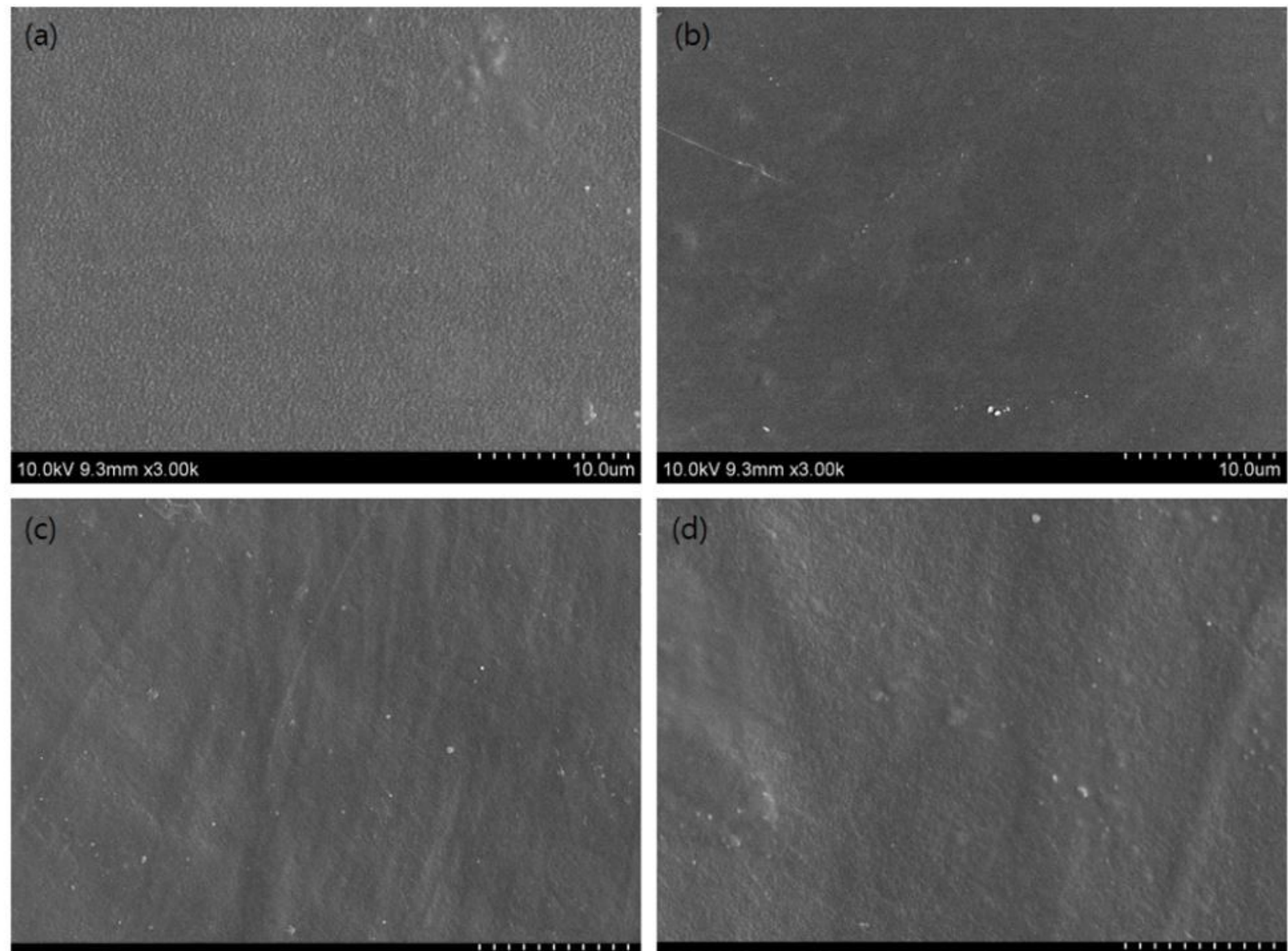

\section{Figure 6}

SEM images of composites having: (a) only CP, (b) 1:0.5 CP/PU, (c) 1:1 CP/PU, and (d) 1:1 CP/PU with 10 wt\% curcumin. 

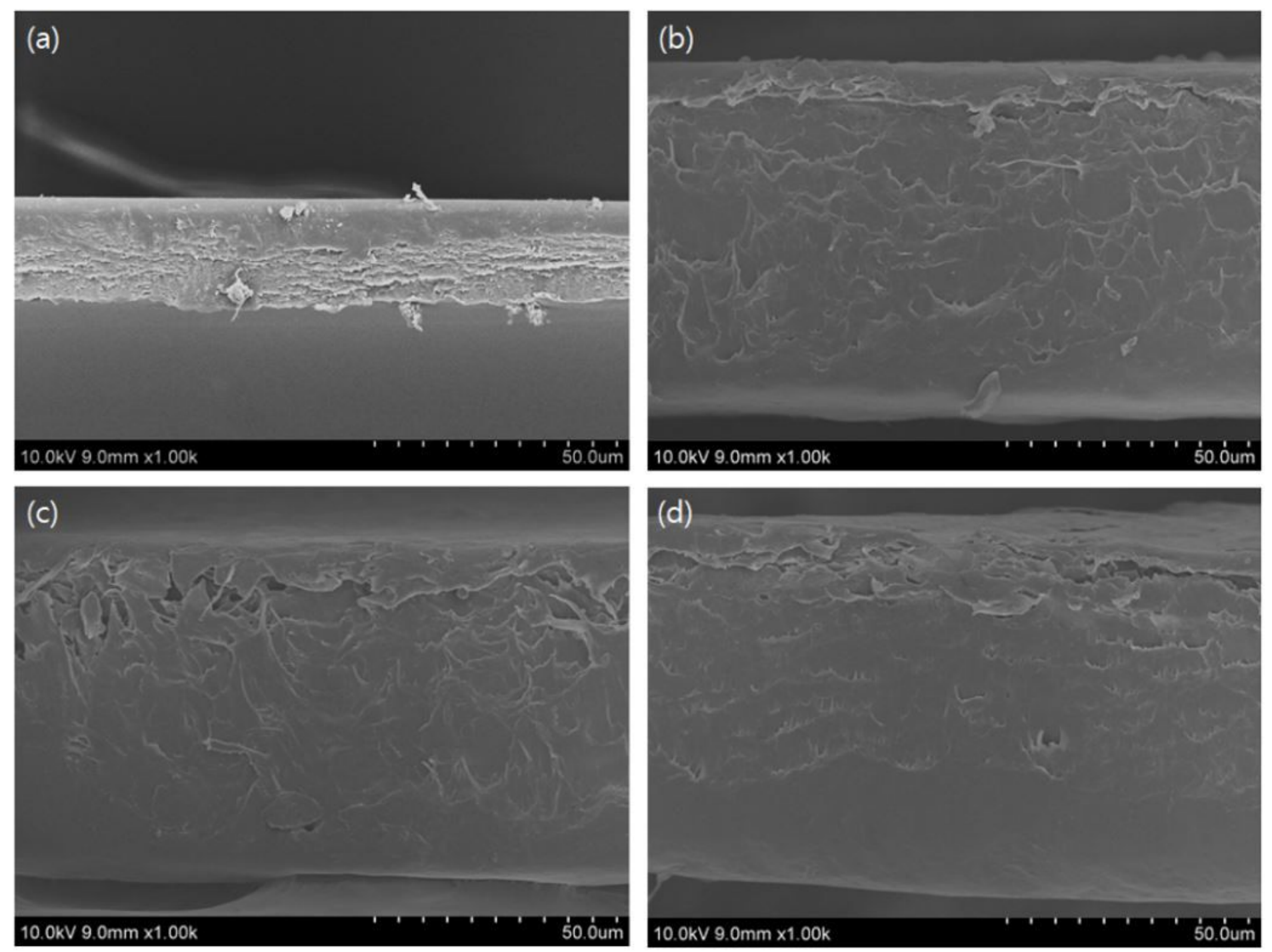

\section{Figure 7}

Cross-sectional SEM images of composites having: (a) only CP, (b) 1:0.5 CP/PU (c) 1:1 CP/PU, and (d) 1:1 CP/PU with 10 wt\% curcumin. 


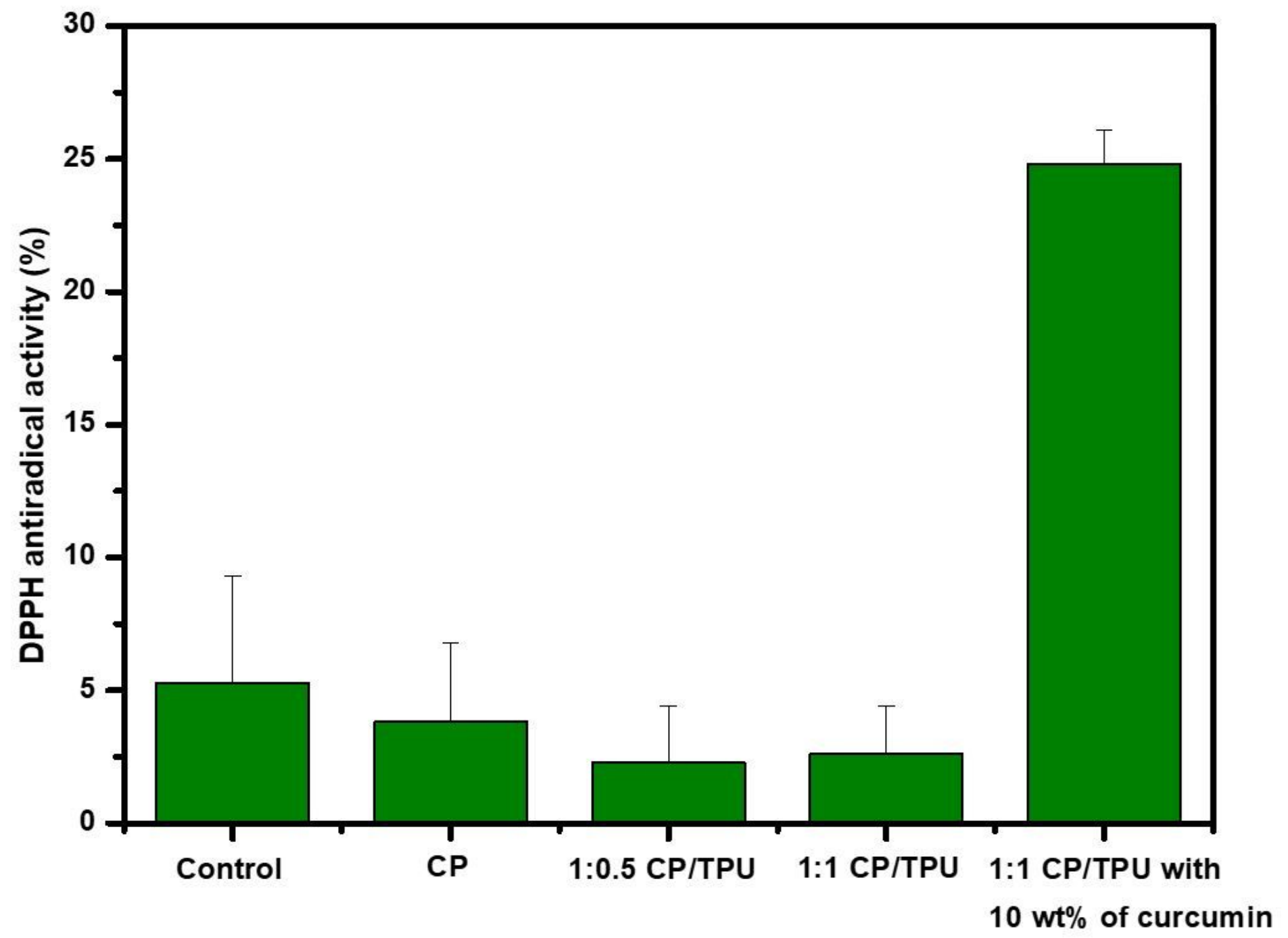

Figure 8

DPPH radical scavenging activity of composites. 


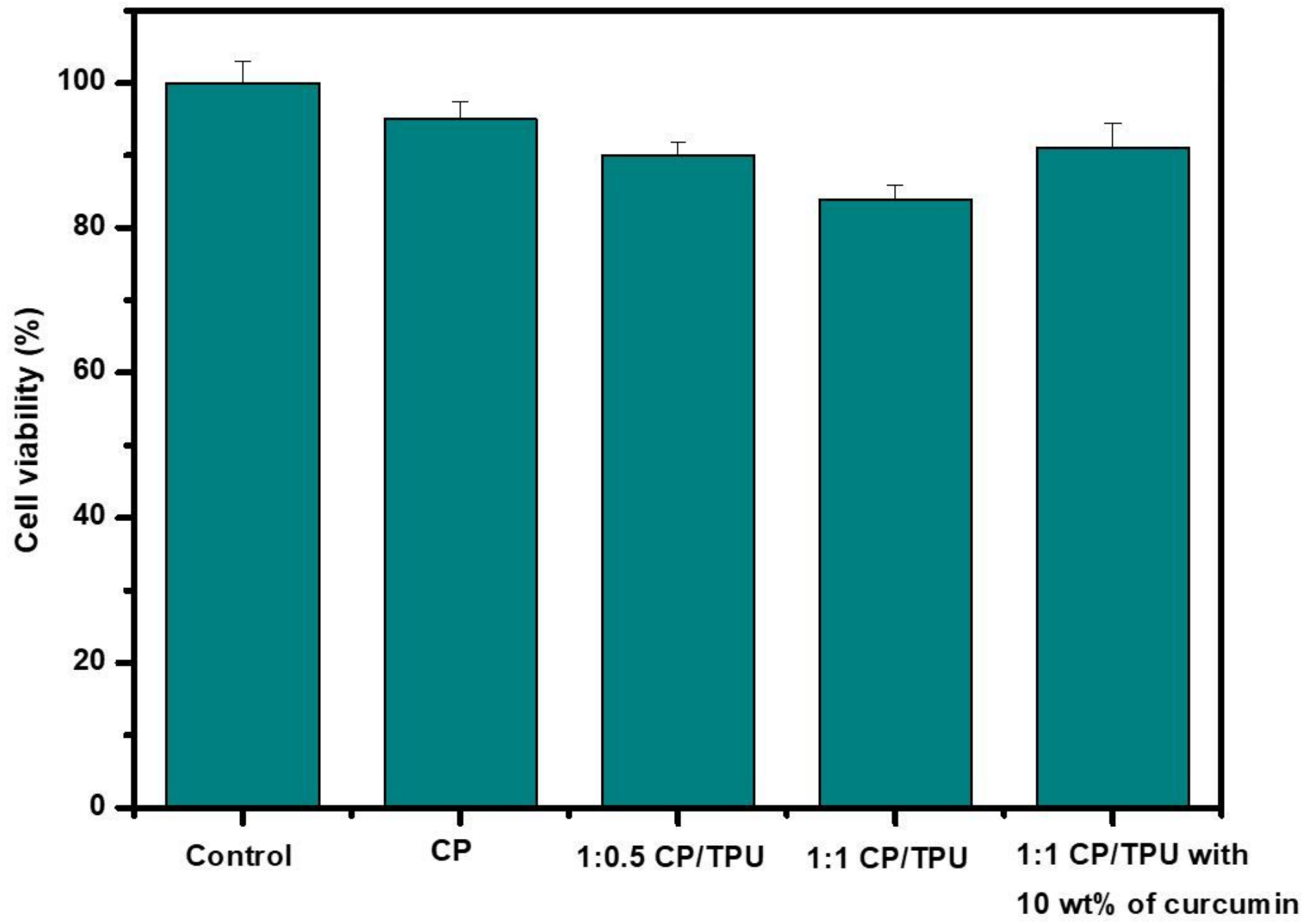

Figure 9

Cell viability of HaCaT cell line for composites. 

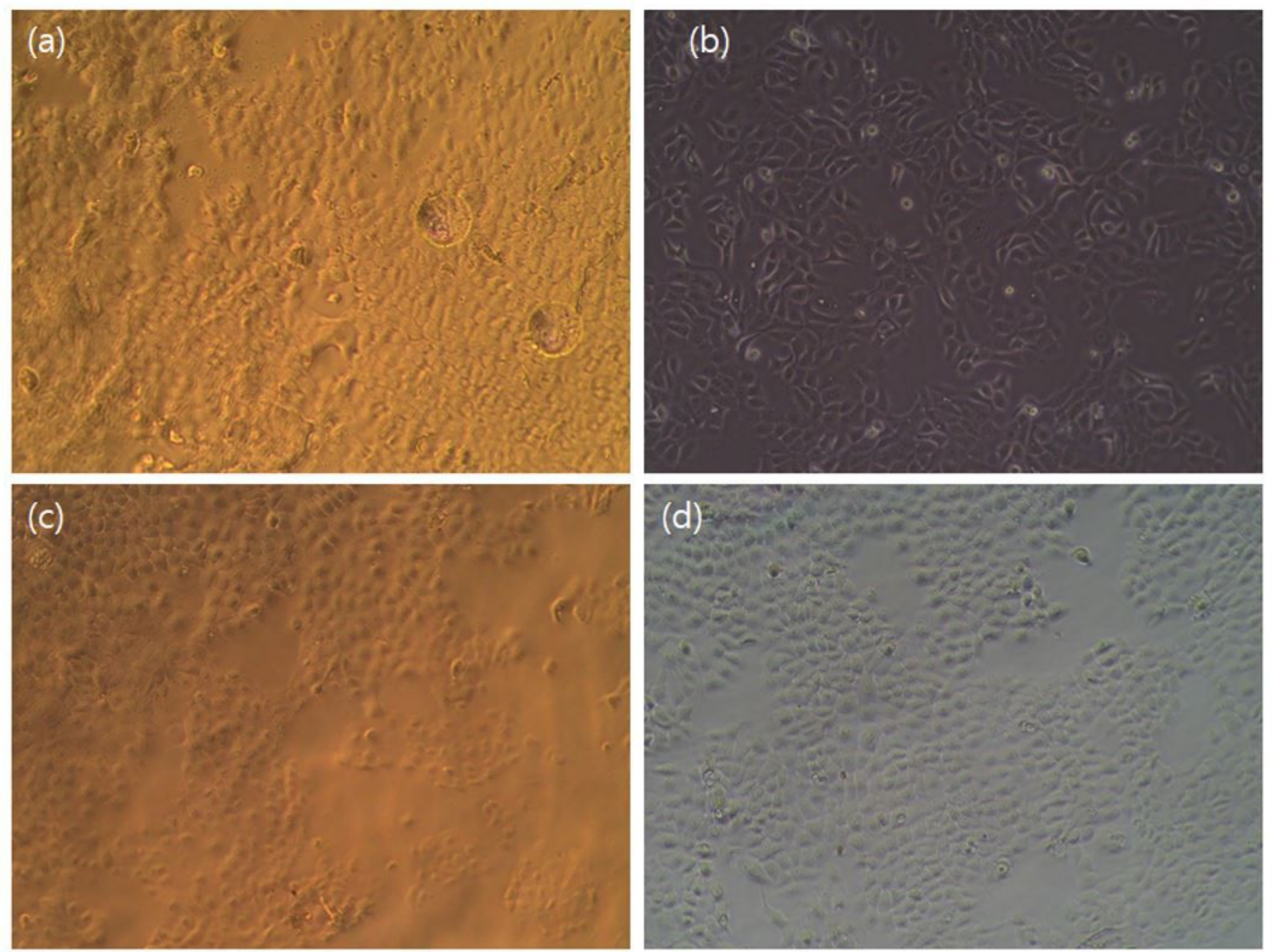

Figure 10

Light microscopy images of HaCaT cell line for composites having: (a) only CP, (b) 1:0.5 CP/PU, (c) 1:1 $\mathrm{CP} / \mathrm{PU}$, and (d) 1:1 CP/PU with $10 \mathrm{wt} \%$ curcumin.

\section{Supplementary Files}

This is a list of supplementary files associated with this preprint. Click to download.

- supportinginformation.docx 